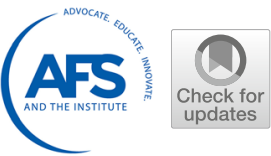

\title{
THE DISTRIBUTION OF CARBON IN AUSTENITE STUDIED ON A WATER-QUENCHED COMPACTED GRAPHITE IRON USING ELECTRON PROBE MICROANALYSIS
}

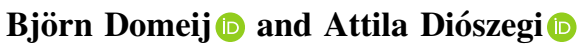 \\ Department of Materials and Manufacturing, Jönköping University, Gjuterigatan 5, 55111 Jönköping, Sweden
}

Copyright (C) 2020 The Author(s)

https://doi.org/10.1007/s40962-020-00425-2

\begin{abstract}
Spheroidal graphite is the defining microstructural feature of ductile iron and also plays an important role in compacted graphite iron. It is widely accepted that graphite spheroids are engulfed by austenite at an early stage of solidification after which their growth is impeded by the slow diffusion of carbon through a layer of austenite. In this work, a compacted graphite iron-containing spheroidal graphite was studied after interruption of its solidification by water quenching. Selected areas of a cross section of the castings were investigated using quantitative electron probe microanalysis, with emphasis on the distribution of carbon in austenite. The measured carbon concentration near graphite was generally below the the-

the low measured concentrations. The measured carbon concentration near graphite varied by as much as $0.3 \mathrm{wt} \%$, with the lowest concentrations consistently found in the central region of compacted graphite-austenite eutectic cells. Regardless of whether these differences were present prior to quenching or are consequences thereof, they seem to reflect either departures from, or displacements of, the carbon concentration in austenite at equilibrium with graphite. This indicates that there is something about growth of graphite embedded in austenite which is not well understood. Concentrations of $\mathrm{Si}, \mathrm{Mn}$ and $\mathrm{Cu}$ are near equal in the compared regions and do not explain the observed differences in carbon content near graphite.
\end{abstract} oretical carbon concentration in austenite at equilibrium with graphite at $1140{ }^{\circ} \mathrm{C}$. Numerical simulations of diffusion of carbon in austenite around spheroidal graphite suggest that a zone of austenite around graphite was likely depleted of carbon during quenching, possibly explaining
Keywords: cast iron, solidification, carbon, austenite, electron probe microanalysis, wavelength-dispersive spectroscopy

\section{Introduction}

Spheroidal graphite iron (SGI), also known as ductile iron, owes its strength and ductility to the rounded morphology of graphite particles in the material. Spheroidal graphite (SG) is also typically found in compacted graphite iron (CGI), where the relative amount of SG and compacted graphite (CG) has strong influence on material properties.

Computer simulation of casting processes has become an important tool for product designers and foundry engineers to anticipate manufacturing problems at an early stage of product development. As SG is the characteristic solidification unit defining SGI and also in CGI, its growth is

This paper is an invited submission to IJMC selected from presentations at the 2nd Carl Loper 2019 Cast Iron Symposium held September 30 to October 1, 2019, in Bilbao, Spain. essential in order to simulate the casting process and predict local microstructure and properties for a component of these materials.

Research has shown that SG may nucleate independent of austenite $(\gamma)$ in the melt on nonmetallic particles which are typically found at their center. ${ }^{1-6}$ SG may grow separate from $\gamma$ for a period even when $\gamma$ is the primary solid phase. However, at a relatively early stage, $\gamma$ and graphite begin to interact. The $\gamma$ grows around the SG particles, forming a barrier which separates them from the melt. ${ }^{7,8}$

Based on the assumption that the radius of a SG particle grows as fast as allowed by the diffusion of carbon to its interface, growth laws were proposed for SG in liquid as well as in a shell of $\gamma^{7}$ The diffusion process was assumed to occur under quasi-steady state, that is, changes to 
boundary conditions were assumed to be slow relative to the time it takes to reach steady state.

Since then, various improvements have been made to this model, ${ }^{9-15}$ such as accounting for the diffusion of carbon in the liquid and interaction with growth of dendritic $\gamma$ and neighboring spheroids.

Most models presume that the carbon concentrations at the interfaces between $\gamma$, graphite and liquid are in local equilibrium and can be extracted from an equilibrium phase diagram. Some authors have attempted to investigate the importance of interface curvature and attachment kinetics at the graphite interface. ${ }^{16}$ Based on comparison of simulated and experimental cooling curves and size distributions of $\mathrm{SG}$, researchers have concluded that, regardless of whether SG grows in liquid or a shell of $\gamma$, interface kinetics are important for its growth up to a radius of about $1.5 \mu \mathrm{m}$. For greater radii, the authors concluded that growth becomes increasingly controlled by volume diffusion.

The present article seeks to challenge the conventional understanding of the solidification process of CGI by studying the distribution of carbon in $\gamma$ during the material's solidification. A cast iron was allowed to solidify to a certain extent at moderate cooling conditions, after which it was quenched in water, such as to preserve the distribution of carbon down to room temperature. The distribution of carbon was then studied over a cross section of the material using electron probe microanalysis. The migration of carbon during the quenching process is estimated using numerical and analytical methods to evaluate how well the distribution of carbon was preserved through the quenching process.

\section{Experimental}

Cylindrical samples of $400 \mathrm{~g}$ were machined from a ductile iron of composition according to Table 1. These samples were placed in $\varnothing 40-\mathrm{mm}$ alumina crucibles and subsequently remelted and solidified in a laboratory furnace under argon atmosphere as has been described in detail in earlier work. ${ }^{17,18}$ During the remelting procedure, the melt was held for $60 \mathrm{~min}$ at around $1450{ }^{\circ} \mathrm{C}$. After the holding time, the furnace was turned off and the sample inside

Table 1. Chemical Composition in Weight Percent Measured Using Optical Emission Spectroscopy. CE = $\mathrm{C}+(\mathrm{Si}+\mathrm{P}) / 3$

\begin{tabular}{lllllllll}
\hline $\mathrm{CE}$ & $\mathrm{C}$ & $\mathrm{Si}$ & $\mathrm{Mn}$ & $\mathrm{P}$ & $\mathrm{S}$ & $\mathrm{Cu}$ & $\mathrm{Sn}$ & $\mathrm{Mg}$ \\
\hline 4.22 & 3.74 & 1.88 & 0.64 & 0.004 & 0.012 & 0.80 & 0.14 & 0.06 \\
\hline
\end{tabular}

began to cool and eventually solidify. Due to fading of the melt treatment during the remelting procedure, the material solidifies as a CGI.

In a preliminary set of experiments, cooling curves were recorded using S-type thermocouples protected with quartz glass tubes. The hot junctions of the thermocouples were positioned at a height of $20 \mathrm{~mm}$ over the bottom of the crucibles corresponding to roughly half the height of the liquid metal, one near the center line of the cylinder and one resting against the crucible wall. The temperature recordings shown in Figure 1 indicated that cooling conditions were such that the solidification time was around $10 \mathrm{~min}$.

After the preliminary experiments, the remelting procedure was repeated with new SGI samples machined from the same casting, this time without the presence of thermocouples. Instead, the stable eutectic solidification was interrupted by quenching the solidifying material in water, forcing residual liquid to solidify as the metastable $\gamma$-cementite eutectic in the form of a fine microstructure called ledeburite. The quenching was performed by removing the bottom lid from the furnace, allowing the alumina crucible along with its content to drop into a large bath of water, agitated by a strong water pump.

After the quenching, the cylinders were cut in half using wet abrasive cutting, exposing a circular cross section of the material. The bottom half was hot mounted, ground and polished. Grinding was performed by hand using silica paper on a rotating disk down to a grit of 2000 FEPA-P. The polishing was performed in an automated device, first on a satin woven cloth using a $3-\mu \mathrm{m}$ diamond suspension,

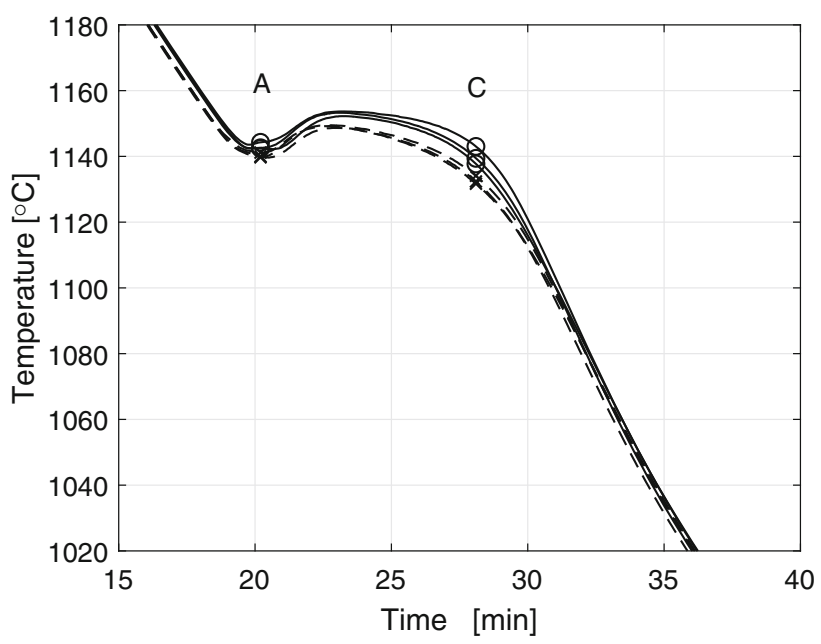

Figure 1. Cooling curves recorded during preliminary experiments. Solid curves were measured near the center of the casting. Dashed curves were measured near the surface. Circles and crosses denoted (a) and (c) indicate the time by which specimens were quenched during later experiments. 
followed by polishing on napped cloth using a $1-\mu \mathrm{m}$ diamond suspension. A brief third polishing step on napped cloth and $1-\mu \mathrm{m}$ diamond suspension at low pressure was applied to achieve a slight etching effect to facilitate differentiation of phases during light microscopy. ${ }^{19}$

On each cross section, two $600 \times 600 \mu \mathrm{m}$ regions were selected for investigation using EPMA, one near the edge and another near the center of the cross section, both containing spheroidal and CG. The regions were marked using Vickers hardness indentations in an L-shaped pattern which could be easily distinguished from the surrounding structure. A final polishing step was applied to remove the lightly etched layer of the structure. The mounting was then removed, and the specimens were cleaned thoroughly in ultrasonic baths of gasoline, ethanol, acetone and finally distilled water to remove residual hydrocarbons from the polished surface.

To investigate the composition over the selected regions of the cross section, a modified ARL-SEMQ microprobe was used. The instrument has been extensively modified for specialization in rapid quantitative mapping of chemical composition over large regions. ${ }^{20}$ The probe operates at an acceleration voltage of $25 \mathrm{kV}$ and a sample current of 6 $\mu \mathrm{A}$. Quantitative measurement of the concentration of six elements is achieved using six wavelength-dispersive spectrometers (WDS).

The motorized stage moves the specimen under the stationary electron beam, in a row-by-row zigzag pattern across the intended region, with a row spacing of $2 \mu \mathrm{m}$. Every $2 \mu \mathrm{m}$, the X-ray counts are stored and the counters are reset. The focal beam diameter is $0.8 \mu \mathrm{m}$, and the depth of the interaction zone is about $1 \mu \mathrm{m}$. In this way, every stored X-ray count is approximately representative of a $2 \times 2$ $\mu \mathrm{m}$ region which from here on is referred to as a "pixel." Overlap of pixels is not expected past their nearest neighbors.

Calibration was performed using eight iron-based certified reference standards. Concentration ranges are listed in Table 2. The probe was set up to scan a $2 \times 2 \mathrm{~mm}$ area of the reference standards. Each element was first calibrated using the standard with the highest concentration, making sure the X-ray detector was not flooded. The detector measuring $\mathrm{Fe}$ was shielded to avoid flooding. The

Table 2. Ranges of Concentrations in Reference Materials Used for Calibration

\begin{tabular}{lllllll}
\hline [wt\%] & Fe & C & Si & Mn & Cu & $P$ \\
\hline Min & 92.5 & 0.006 & 0.008 & 0.0057 & 0.0058 & 0.0025 \\
Max & 99.9 & 2.95 & 2.81 & 1.50 & 1.39 & 0.66 \\
\hline
\end{tabular}

calibration was validated by making sure measured values agree with the remaining seven certified reference standards. No considerable deviation from proportionality between counts and concentrations was observed.

\section{Results and Discussion}

Quantitative measurements of carbon using WDS are known to be difficult due to hydrocarbon contamination. ${ }^{21}$ We will for this reason begin by an examination of the accuracy of the measured carbon concentrations. A preliminary analysis of the concentration maps showed that there was a systematic drift in the measured carbon content from the first to the last row. Linear least squares regression suggested a mean slope of $1.015 \times 10^{-3} \mathrm{wt} \% / \mu \mathrm{m}$. All carbon maps were for this reason corrected additively for this slope to eliminate the systematic drift, with the mean concentration over the maps conserved. While a systematic bias of the measured concentration may remain, the procedure makes sure that this bias is fairly uniform over a given map. Relative comparison of carbon concentrations measured in different regions of the map should for this reason be valid, but the accuracy of the absolute concentrations remains uncertain.

A useful point of reference for the carbon concentration in our specimens is the cementite phase found in the regions which were liquid before quenching. Examples of a particularly large cementite particle are shown in Figure 2, which shows a portion of the concentration map from the periphery of specimen C. A histogram of measurements over the particle indicates a peak centered on $6.73 \mathrm{wt} \% \mathrm{C}$. Considering that the stoichiometric carbon concentration of cementite $\left(\mathrm{Fe}^{3} \mathrm{C}\right)$ is $6.69 \mathrm{wt} \%$ (atomic weights taken from

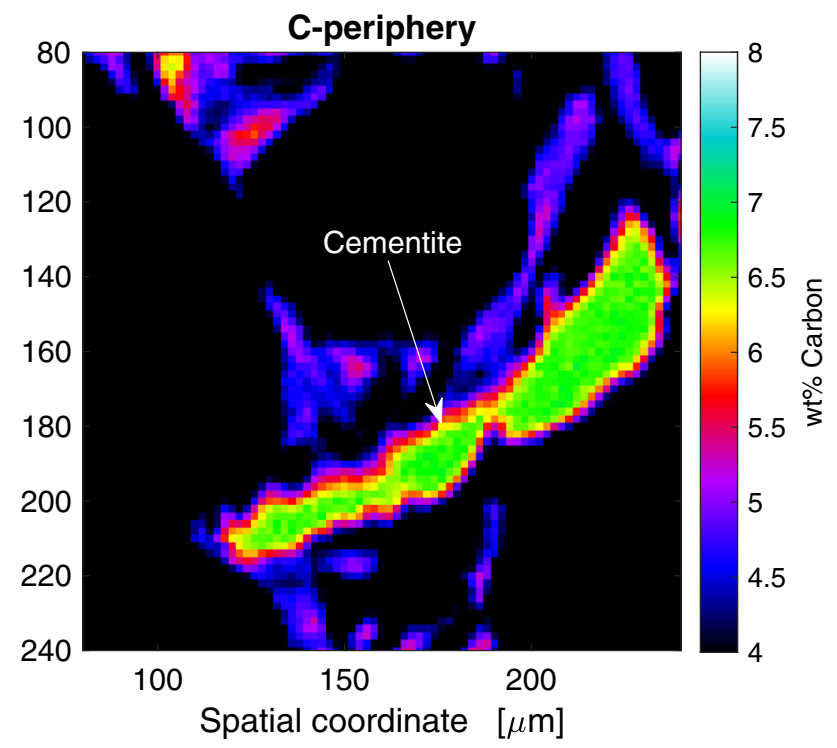

Figure 2. Portion of carbon concentration map obtained using EPMA, showing a large cementite particle. 
Reference 22), the corrected carbon concentrations seem to be reasonably accurate in this concentration range, with an estimated bias of $+0.04 \mathrm{wt} \%$, despite the measured concentration exceeding the calibration range.

The concentration of carbon in $\gamma$ does not obey a stoichiometric ratio and demands a closer investigation.

\section{The Distribution of Carbon in Austenite}

The aim of this section is to highlight the most important observations and discuss their implications. How representative the observed distribution of carbon is of its distribution before quenching and the influence of microsegregation on equilibrium concentrations of carbon will be discussed in later sections.

Figures 3 and 4 show concentration maps of carbon, where the color scale has been adjusted to capture the range of carbon concentrations found in regions which were $\gamma$ prior to quenching (prior $\gamma$ ). SG and CG can be observed, embedded in the prior $\gamma$. Ledeburite regions, which were liquid prior to quenching, generally overshoot the color scale and are hence shown as white, as does graphite.
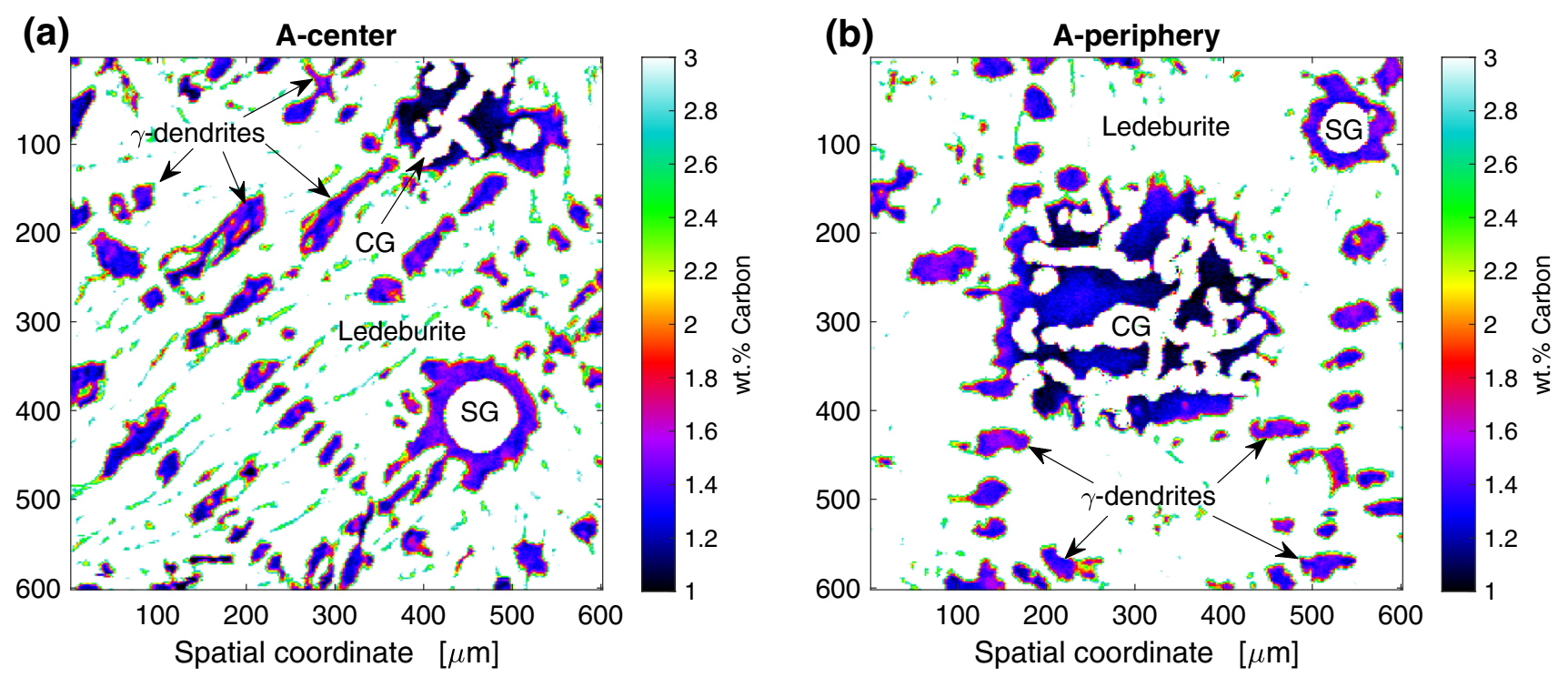

Figure 3. Carbon concentration maps measured using EPMA. Locations of maps (a) and (b) are from the center and periphery, respectively, of the cross section of specimen A (see Figure 1). SG: spheroidal graphite. CG: compacted graphite.
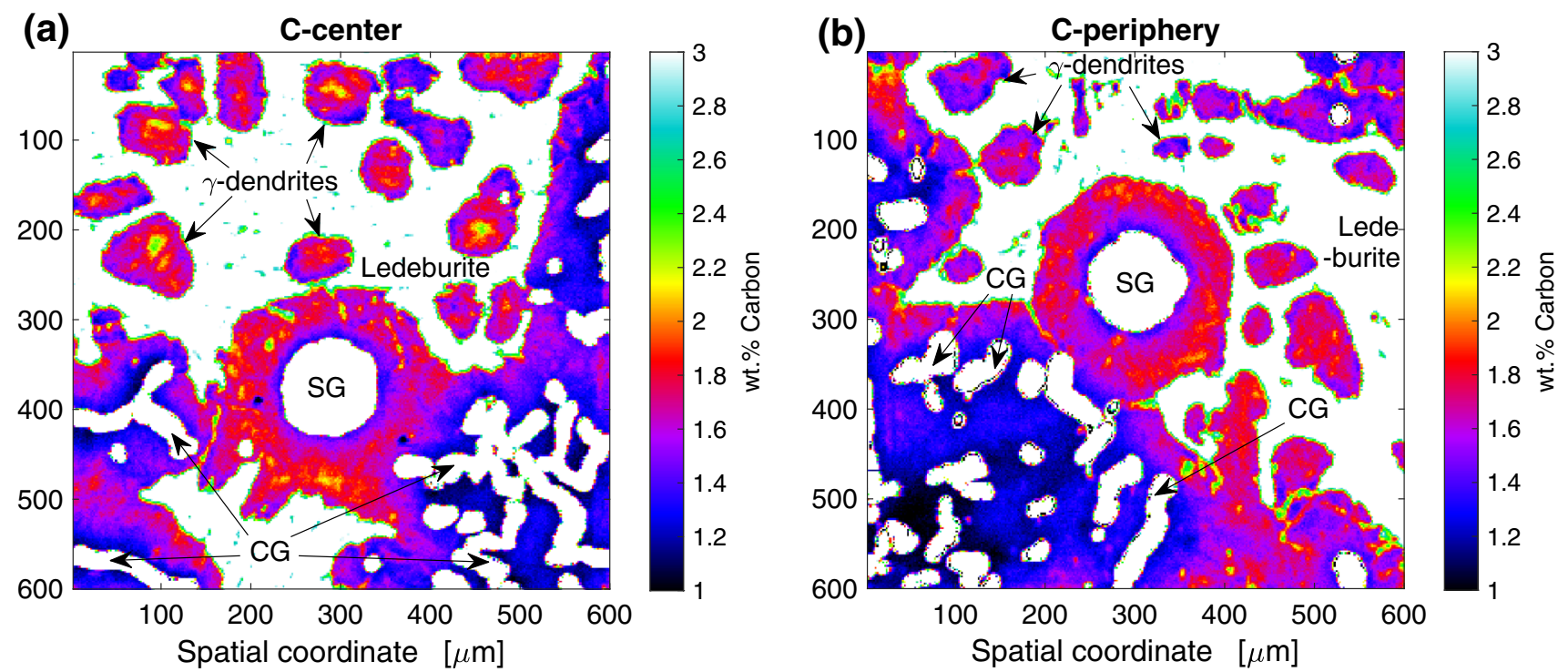

Figure 4. Carbon concentration maps measured using EPMA. Locations of maps (a) and (b) are from the center and periphery, respectively, of the cross section of specimen C (see Figure 1). SG: spheroidal graphite. CG: compacted graphite. 
The highest carbon concentrations in prior $\gamma$ are generally measured near the liquid, while lower concentrations are generally found near graphite. This is reasonable, considering that the carbon concentration of $\gamma$ in equilibrium with liquid $C_{\mathrm{C}}^{\gamma / L}$ rises above the concentration in equilibrium with graphite $C_{\mathrm{C}}^{\gamma / G}$ at undercooling below the eutectic temperature, as illustrated using a binary $\mathrm{Fe}-\mathrm{C}$ phase equilibrium diagram in Figure 5.

The carbon concentrations of $\gamma$ are naturally lower than indicated in Figure 5 for our present multi-component alloy containing $1.88 \mathrm{wt} \% \mathrm{Si}$. For reference, the carbon concentration in $\gamma$ at equilibrium with liquid $C_{\mathrm{C}}^{\gamma / L}$ is $1.85 \mathrm{wt} \%$ at $1140{ }^{\circ} \mathrm{C}$ according to the expression $C_{\mathrm{C}}^{\gamma / L}=(1528.4-T) / 177.9-0.18 \times C_{\mathrm{Si}},{ }^{23}$ where $C_{C}^{\gamma / L}$ and $C_{S i}$ are concentrations in weight percent and $\mathrm{T}$ is the temperature in Celsius.

The skewed couple zone of cast irons may drive the carbon concentrations of liquid to exceed the eutectic concentration, which may in turn impact the carbon concentration in $\gamma$ in local equilibrium with the liquid. ${ }^{24,25}$ Partitioning of carbon between martensite and $\gamma$ during the quenching procedure may also have caused small zones of carbon depletion and supersaturation, as will be discussed in a later section of this paper.

We will now direct our attention toward the concentration of carbon in $\gamma$ near graphite. Assuming uniform temperature, pressure and distribution of substitutional elements over the $\gamma, C_{\mathrm{C}}^{\gamma / G}$ is expected to also be uniform. On the contrary, Figures 3 and 4 indicate that the concentration of carbon in $\gamma$ near graphite varies considerably. The lowest concentrations of carbon, around $1.0 \mathrm{wt} \%$, are consistently found in $\gamma$ in the interior of CG- $\gamma$ eutectic cells, which can

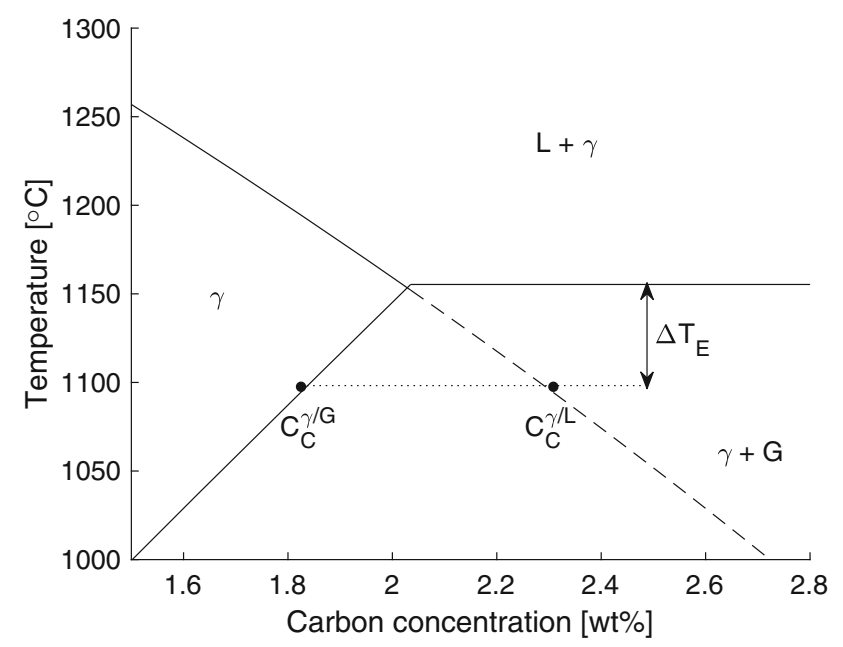

Figure 5. Illustration of the divergence of carbon concentrations in austenite at equilibrium with graphite $C_{\mathrm{C}}^{\gamma / G}$ and liquid $C_{\mathrm{C}}^{\gamma / L}$ at undercooling $\Delta T_{\mathrm{E}}$ below eutectic temperature, for a binary $\mathrm{Fe}-\mathrm{C}$ equilibrium phase diagram. be observed as black and dark blue regions in Figures 3 and 4. Meanwhile, the measured carbon concentrations barely fall below $1.3 \mathrm{wt} \%$ near SG nor near the extremities of $\mathrm{CG}$ in the periphery of $\mathrm{CG}-\gamma$ cells.

The carbon concentration of $\gamma$ in contact with graphite is by necessity either in local equilibrium or it is not. Hence, the observed variations in the carbon concentration of $\gamma$ in contact with graphite likely reflect some combination of (1) departure from or (2) displacement of the carbon concentration in $\gamma$ at equilibrium with graphite.

A departure from the equilibrium concentration could arise if the attachment kinetics of carbon to graphite is slow relative to the transport of carbon toward its surface. Displacement of the carbon concentration in $\gamma$ at equilibrium with graphite could relate to local stresses or variations in chemical composition of $\gamma$ due to microsegregation.

Whichever is the case, we must also consider at what stage the observed distribution of carbon developed. Is it representative of the distribution of carbon in $\gamma$ prior to quenching, or was the distribution altered during the quenching process?

The potential influences of microsegregation and the quenching procedure on the observed distribution of carbon are discussed in the following sections, after which conclusions are summarized.

\section{Consideration of Substitutional Elements}

In cast irons, the silicon concentration is typically higher early compared to late crystallized $\gamma^{26-30}$ This is due to the tendency of $\mathrm{Si}$ to partition at higher concentrations in $\gamma$ than liquid during solidification, as well as its low diffusivity in $\gamma$ making it resistant to back-diffusion. ${ }^{31}$ Since silicon is known to strongly affect the equilibrium concentrations of carbon in $\gamma,{ }^{23}$ its microsegregation in $\gamma$ is important to consider when evaluating local carbon contents.

Figure 6 shows the measured map of $\mathrm{Si}$ concentrations corresponding to the region shown in Figure 4b). A comparison of the Si concentration in the low-carbon region in the interior of the CG- $\gamma$ eutectic cell with the silicon concentration near the SG (dashed circles) shows that both display a color in the yellow range, indicating a silicon concentration of about $2.3 \mathrm{wt} \%$.

The influence of $\mathrm{Mn}$ and $\mathrm{Cu}$ on equilibrium concentrations of carbon in $\gamma$ is considerably weaker than of $\mathrm{Si}$, and their concentrations were also found to be similar in the two regions. The concentration of $P$ is very low in the compared regions. 


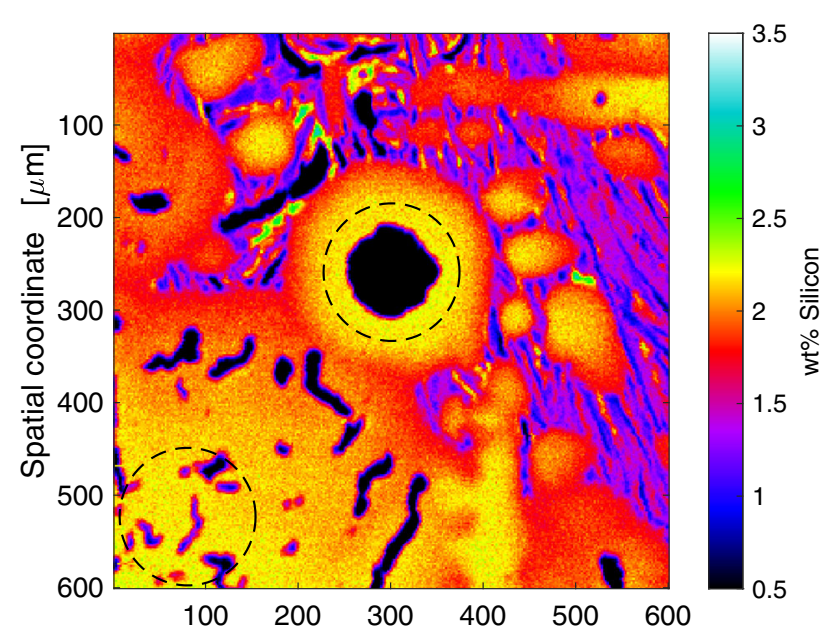

Figure 6. Silicon concentration map measured using EPMA of a region in the periphery of specimen $C$, corresponding to Figure $4 b$. Dashed circles indicate compared regions.

As the composition of $\gamma$ near SG and in the central region of CG- $\gamma$ eutectic cells seems to be essentially the same aside from carbon, no displacement of the concentration of carbon at equilibrium with graphite can be expected on the basis of microsegregation. We can conclude that the observed differences in carbon concentration appear to have no relation to microsegregation of $\mathrm{Si}, \mathrm{Mn}$ and $\mathrm{Cu}$, which are the main substitutional alloying elements in the alloy.

\section{Migration of Carbon During Quenching}

There is a risk that the observed distribution of carbon differs from the distribution during solidification due to migration during the water quenching. To investigate how the quenching process influenced the distribution of carbon, a numerical simulation of the diffusion of carbon in $\gamma$ around SG was performed. The simulation employed a control volume-based implicit finite difference method based on Fick's law of diffusion for one dimension in a spherical coordinate system, essentially the same as described for heat conduction but for chemical rather than thermal diffusivity. ${ }^{32}$ The concentration- and temperaturedependent diffusivity was updated explicitly every time step according to an equation by Ågren. ${ }^{33}$ The contribution of concentration gradients of substitutional elements to the driving force for diffusion of carbon, i.e., thermodynamic factors, is neglected. ${ }^{34}$ This is fair as these gradients are small in early crystallized $\gamma$.
The simulation was performed in two steps: (1) an isothermal hold at $1140{ }^{\circ} \mathrm{C}$ for $60 \mathrm{~s}$, allowing the concentration profile to reach steady state, and (2) a global temperature drop at a constant rate of $-300 \mathrm{~K} / \mathrm{s}$, representing the quenching. The cooling rate during the quenching is uncertain, but experience from conducting the experiments suggests that the sound of boiling lasts only for a few seconds. The chosen cooling rate giving $3.5 \mathrm{~s}$ to reach $100{ }^{\circ} \mathrm{C}$ is thus reasonable.

As we are mainly interested in the carbon concentration near graphite, the concentration is kept constant at $1.84 \mathrm{wt} \%$ on the exterior boundary against the liquid.

At the interior boundary, against the SG, the consumption of carbon associated with growth of graphite is represented by a flux of carbon $j$, which is assumed to be controlled by $j=-K_{\mathrm{C}}\left(w_{\mathrm{C}}-w_{\mathrm{C}}^{\gamma / G}\right)$, where $K_{\mathrm{C}}$ is a proportionality constant, $w_{\mathrm{C}}$ is the simulated boundary concentration and $w_{\mathrm{C}}^{\gamma / G}$ is the carbon concentration in $\gamma$ at equilibrium with graphite. The flux condition was integrated into the implicit solver for concentrations. The authors were not able to find an adequate expression for $C_{\mathrm{C}}^{\gamma / G}$ as a function of $\mathrm{T}$ and $\mathrm{Si}$ in the literature. An expression was developed by fitting a bivariate second-order polynomial to the $C_{\mathrm{C}}^{\gamma / G}$ surface in the $\mathrm{Fe}-\mathrm{C}-\mathrm{Si}$ system at atmospheric pressure calculated using Thermo-Calc 2019a with the TCFE7 databank for the temperature range 400 to $1200{ }^{\circ} \mathrm{C}$ and 0 to $10 \mathrm{wt} \% \mathrm{Si}$. Using the coefficients given in Table 3, the expression (1) provides $C_{\mathrm{C}}^{\gamma / G}$ within a standard deviation of $4 \times 10^{-4}$ wt $\%$ from the Thermo-Calc results. The carbon concentration in $\gamma$ at equilibrium with graphite $C_{\mathrm{C}}^{\gamma / G}$ and the average silicon concentration of the system $C_{\mathrm{Si}}^{L}$ are given in weight percent, and the temperature $T$ is given in ${ }^{\circ} \mathrm{C}$.

$$
\begin{aligned}
C_{\mathrm{C}}^{\gamma / G}= & a_{1}+a_{2} C_{\mathrm{Si}}^{\gamma}+a_{3}\left(C_{\mathrm{Si}}^{\gamma}\right)^{2} \\
& +\left(a_{4}+a_{5} C_{\mathrm{Si}}^{\gamma}+a_{6}\left(C_{\mathrm{Si}}^{\gamma}\right)^{2}\right) T \\
& +\left(a_{7}+a_{8} C_{\mathrm{Si}}^{\gamma}+a_{9}\left(C_{\mathrm{Si}}^{\gamma}\right)^{2}\right) T^{2}
\end{aligned}
$$

Eqn. 1

The value of $K_{\mathrm{C}}$ is unknown; however, it has been suggested that, just like diffusivity, interface mobility has an Arrhenius type relationship to temperature. ${ }^{35}$ A clue can be derived from the fact that, under conventional cooling conditions, precipitation of graphite is known to continue by desaturation of $\gamma$ as $C_{\mathrm{C}}^{\gamma / G}$ drops with temperature. ${ }^{36,37}$ Further precipitation of graphite also occurs at lower temperatures when $\gamma$ transforms to ferrite. ${ }^{36,38}$ This indicates that interface kinetics are still considerable at

Table 3. Fitted Coefficients for Eqn. 1

\begin{tabular}{lllllll}
\hline$a_{1}$ & $a_{2}$ & $a_{3}$ & $a_{4}$ & $a_{5}$ & $a_{6}$ & $a_{7}$ \\
\hline $5.283 \times 10^{-2}$ & $\begin{array}{l}4.975 \\
\times 10^{-2}\end{array}$ & $\begin{array}{l}2.580 \\
\times 10^{-4}\end{array}$ & $\begin{array}{l}-7.698 \\
\times 10^{-4}\end{array}$ & $\begin{array}{l}-1.375 \\
\times 10^{-4}\end{array}$ & $\begin{array}{l}2.072 \\
\times 10^{-6}\end{array}$ & $\begin{array}{l}2.166 \\
\times 10^{-6}\end{array}$ \\
\hline
\end{tabular}


temperatures well below the freezing temperature. Trial and error showed that $K_{\mathrm{C}}=10^{-11} \mathrm{~ms}^{-1} \mathrm{wt} \%^{-1}$ was sufficient to maintain an interface concentration near $C_{\mathrm{C}}^{\gamma / G}$, while $K_{\mathrm{C}}=10^{-12} \mathrm{~ms}^{-1} \mathrm{wt}^{-1}$ allowed for notable departure from $C_{\mathrm{C}}^{\gamma / G}$ at steady state. For simplicity, $K_{\mathrm{C}}$ is kept constant during the simulation.

Simulation results for $K_{C}=10^{-11}$ and $K_{\mathrm{C}}=10^{-12}$ are presented in Figures 7 and 8, respectively, in the form of concentration profiles as a function of distance from the SG. In the vicinity of the graphite, calculated steady-state concentration profiles do not fall below the theoretical $C_{\mathrm{C}}^{\gamma / G}$ of $1.58 \mathrm{wt} \%$. The measured carbon concentrations near SG approaching $1.3 \mathrm{wt} \%$ are thus considerably lower than

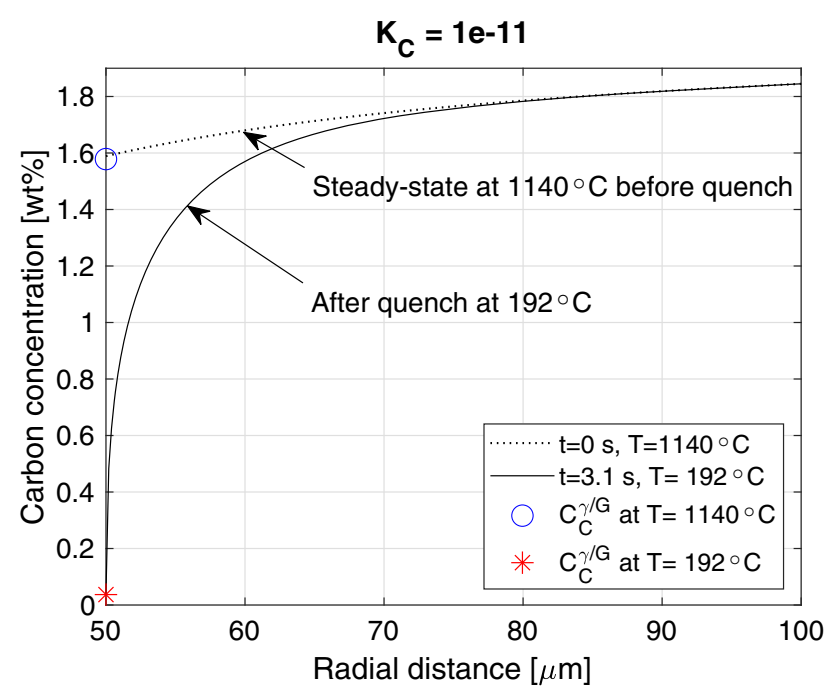

Figure 7. Simulated carbon concentration profile outside SG before and after quenching, for $K C=10^{-11}$ and a quench rate of $-300 \mathrm{~K} / \mathrm{s}$.

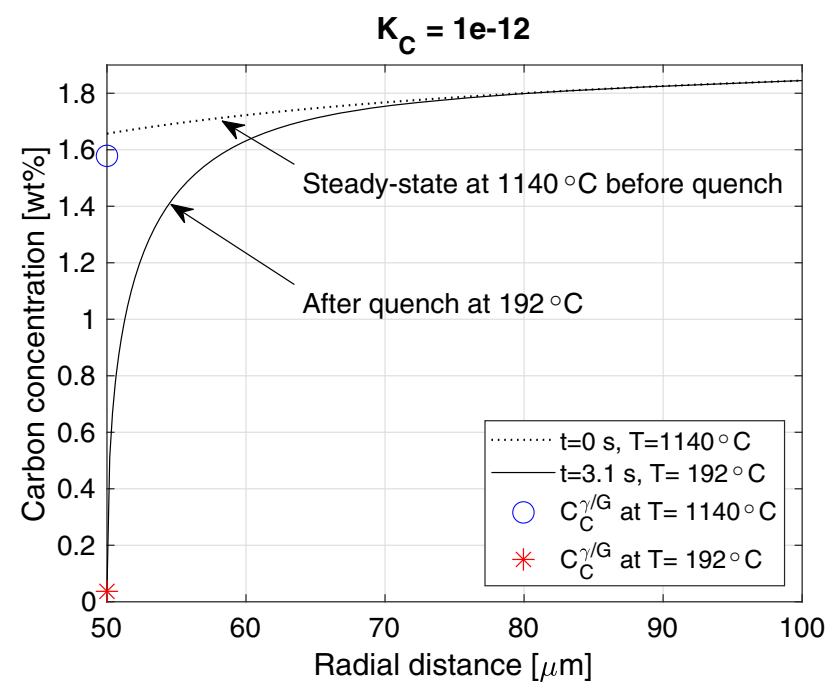

Figure 8. Simulated carbon concentration profile outside SG before and after quenching, for $K C=10^{-12}$ and a quench rate of $-300 \mathrm{~K} / \mathrm{s}$. expected for the steady-state concentration profile at $1140{ }^{\circ} \mathrm{C}$.

Despite the relatively rapid cooling, the numerical calculations suggest that the concentration profile changes substantially during the quenching process. As temperature drops, $C_{\mathrm{C}}^{\gamma / G}$ quickly falls, causing depletion of carbon in the vicinity of the graphite. Despite the parallel fall of diffusivity (from $3.1 \times 10^{-10} \mathrm{~m}^{2} / \mathrm{s}$ at $1140{ }^{\circ} \mathrm{C}$, to $6.6 \times 10^{-22} \mathrm{~m}^{2} / \mathrm{s}$ at $192{ }^{\circ} \mathrm{C}$ ), carbon migrates enough for the depleted zone to extend about $20 \mu \mathrm{m}$ away from the graphite interface.

According to Figures 7 and 8, the carbon concentration at the interface tends to catch up with $C_{\mathrm{C}}^{\gamma / G}$ during quenching, resulting in carbon concentrations far below the $1.3 \mathrm{wt} \%$ measured around SG. The portion of the profile which is below $1.3 \mathrm{wt} \%$ extends about $3-4 \mu \mathrm{m}$ which is near the resolution of the microprobe. In other words, it seems possible that the lowest concentrations closest to the graphite were not captured accurately with EPMA due to bleeding of information from the nearby graphite. It is also important to consider that the choice of $K_{\mathrm{C}}$ is probably unrealistic and is likely in part responsible for the shape of the calculated concentration profiles after the quench. That carbon concentration seems to catch up with $C_{\mathrm{C}}^{\gamma / G}$ near the graphite during the quench, even when a departure is observed at steady state $\left(K_{\mathrm{C}}=10^{-12}\right)$, is most certainly a consequence of the fall of diffusivity with temperature relative to $K_{\mathrm{C}}$ which remains constant. In reality, $K_{\mathrm{C}}$ likely drops with temperature along with diffusivity, and it is not clear whether quenching promotes departure from or convergence toward $C_{C}^{\gamma / G}$.

The considerably higher carbon concentration near SG compared to the central region of $\mathrm{CG}-\gamma$ eutectic cells is difficult to explain. It may, for example, relate to differences in the graphite at various scales, such as the local access to graphite interface, the topology of the graphite interfaces or its crystallographic structure.

An additional numerical calculation was performed for $K_{\mathrm{C}}=10^{-11}$ and a quench rate of $-3000 \mathrm{~K} / \mathrm{s}$ to investigate to what extent an increase in the quench rate suppresses migration of carbon. The result shown in Figure 9 indicates a carbon-depleted zone around SG limited to a distance of about $7 \mu \mathrm{m}$ from the graphite interface, leaving more of the concentration profile representative of its state before quenching. Such a quench rate may be achieved, for example, by quenching a smaller piece of metal.

In conclusion, concentrations measured in prior $\gamma$ near graphite tend to be considerably lower than the theoretical value for $\gamma$ in equilibrium with graphite at the quenching temperature of $1140{ }^{\circ} \mathrm{C}$. The numerical calculations indicate that this is likely related to depletion of carbon in a zone around graphite during quenching. A feasible 


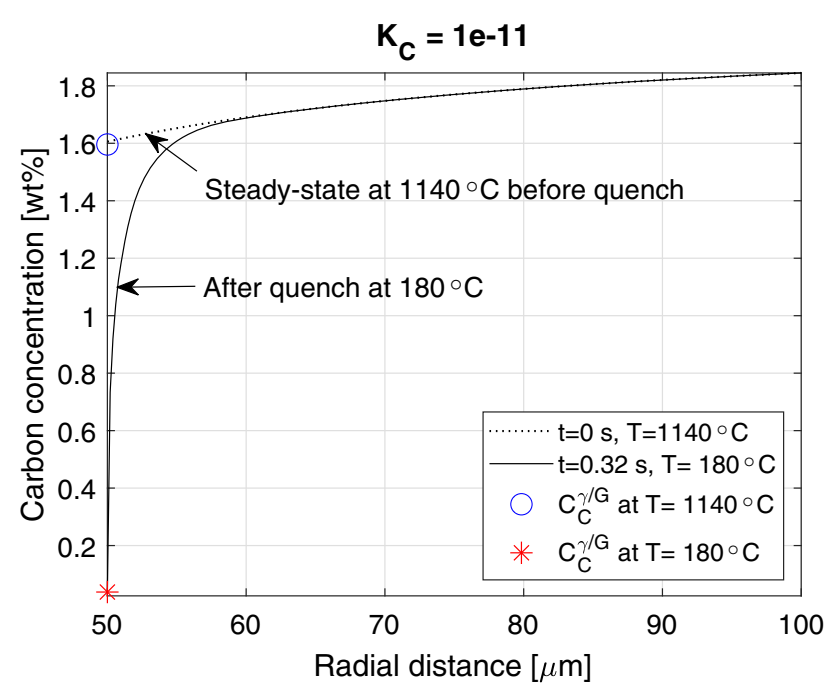

Figure 9. Simulated carbon concentration profile outside SG before and after quenching, for $K C=10^{-11}$ and $a$ quench rate of $-3000 \mathrm{~K} / \mathrm{s}$.

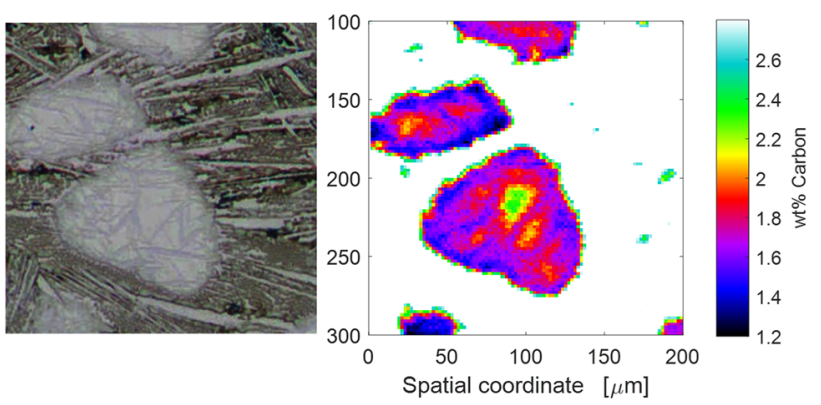

Figure 10. A comparison of a micrograph (left) taken prior to EPMA and the carbon concentration map (right) for the corresponding region. Colorful regions in the concentration map correspond to $\gamma$-dendrites.

approach to better preserve the distribution of carbon through the quenching is to increase the quench rate, for example by reducing the amount of material to quench. The higher concentrations measured in the vicinity of SG compared to the central region of CG- $\gamma$ eutectic cells are difficult to explain.

\section{The Influence of Martensite on the Distribution of Carbon}

The regions which were $\gamma$ prior to quenching display relatively large variations in carbon concentration over distances of a few pixels. Comparison of the distribution of carbon to micrographs indicates that these variations relate to martensite which formed during the water quenching. Figure 10 shows that streaks of lower carbon concentrations correlate with martensite plates, while no martensite is visible in carbon-rich regions.

This is an indication that carbon has partitioned from martensite into the surrounding retained $\gamma$, as has been observed for steels..$^{39,40}$ This means that the distribution of carbon appears to have changed to an extent after martensite transformation. That pale regions between darker needles in dendrite arms correspond to retained $\gamma$ has been verified previously using EBSD in research work on a similar quenched material. ${ }^{41}$

Nital etching was applied to the materials after completion of the EPMA to better observe the distribution of martensite in the material. Unfortunately, the etching failed in the mapped regions, presumably due to local hydrocarbon contamination of the surface. However, inspection of the remainder of the cross-sectional area revealed that the distribution of martensite followed a similar pattern regardless of location. The distribution of martensite in the mapped regions can thus be inferred qualitatively by extrapolation from successfully etched regions. Figure 11 includes micrographs which are representative this pattern.

Figure 11a shows that prior $\gamma$ which is remote from graphite, such as $\gamma$ dendrite arms, generally displays a larger area fraction of retained $\gamma$ (pale regions), traversed by a few thick martensite plates (dark regions).

Moreover, Figure $11 \mathrm{~b}, \mathrm{c}$ shows that regions near CG and SG particles feature more martensite and smaller area fractions of retained $\gamma$.

Given that carbon appears to have partitioned out from the martensite plates into the surrounding $\gamma$, there seems to be a risk that martensite transformation contributed to further migration of carbon. We will for this reason take a closer look at how far carbon is likely to have diffused after martensite formation, using simple diffusion calculations.

We assume that a 4- $\mu$ m-thick plate of martensite forms in $\gamma$ with a uniform carbon content $1.5 \mathrm{wt} \%$ at the temperature for start of martensite transformation $\mathrm{M}_{\mathrm{S}}$. All carbon in the martensite plate is assumed to instantaneously migrate to the interface of the nearby $\gamma$, after which carbon diffuses away from the interface into the $\gamma$ at constant diffusivity. The problem can then be approximated as diffusion along one dimension from an instantaneous point source. The evolution of the carbon profile in the $\gamma$ can be approximated using Eqn. 2:

$C_{\mathrm{C}}(z, t)=C_{\mathrm{C}}^{0}+\frac{M}{\sqrt{4 \pi D_{\mathrm{C}}^{\gamma} t}} \exp \left(-\frac{z^{2}}{4 D_{\mathrm{C}}^{\gamma} t}\right)$

Eqn. 2

where $C_{\mathrm{C}}$ is the concentration of carbon as a function of space and time, $C_{\mathrm{C}}^{0}$ is the initial uniform mass fraction carbon in $\gamma, \mathrm{z}$ is the distance from the martensite plate in meters, $\mathrm{t}$ is the time after martensite formation, $D_{\mathrm{C}}^{\gamma}$ is the constant diffusivity of carbon in $\gamma$ in units of $\mathrm{m}^{2} / \mathrm{s}$ and $\mathrm{M}$ is the amount of carbon displaced from the martensite plate to the $\gamma$-martensite interface. ${ }^{42}$ 

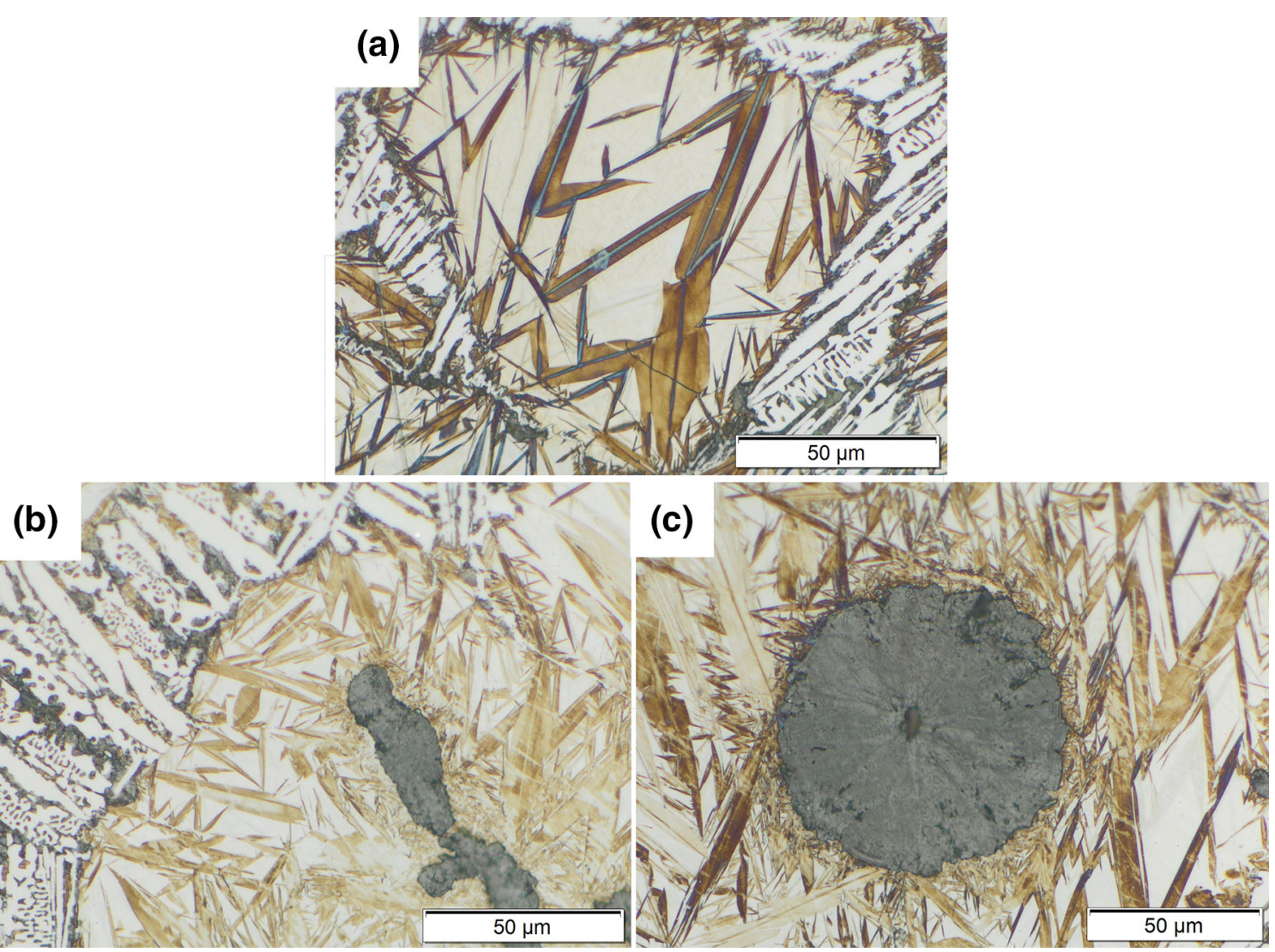

Figure 11. Light optical micrographs of microstructure revealed using Nital etching. Martensite can distinguished as dark needles in (a) a dendrite arm, (b) near CG and (c) near SG.

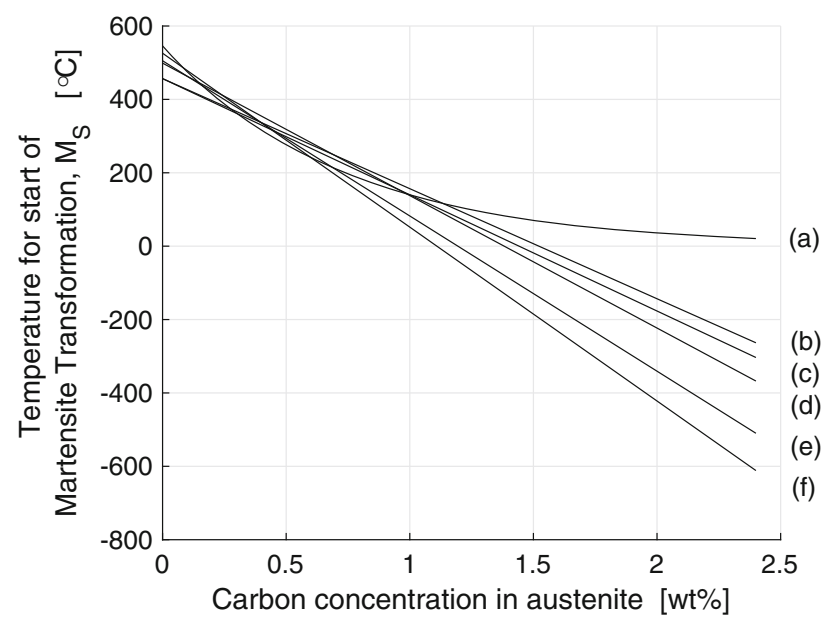

Figure 12. Temperature for start of martensite transformation versus carbon content according to models. (a) is for Fe-C-1.5Si-1.5Mn steels and ${ }^{43}$ (b)-(f) are for mixtures of various steel alloys, ${ }^{44}$ with an added correction for $\mathrm{Si}^{45}$ Input alloying elements are given according to Table 1.

Figure 12 shows the temperature for start of martensite transformation $\mathrm{M}_{\mathrm{S}}$ according to a number of models. The predicted $\mathrm{M}_{\mathrm{S}}$ diverges strongly for carbon concentrations beyond $0.7 \mathrm{wt} \%$ because of the limited calibration range for the models. To avoid extrapolation and underestimation of $D_{\mathrm{C}}^{\gamma}$, we assume a generous $\mathrm{M}_{\mathrm{S}}$ of $200{ }^{\circ} \mathrm{C}$, corresponding to around $0.7 \mathrm{wt} \%$. The carbon concentration of $\gamma$ varies with time and distance from the martensite. For simplicity, a constant $D_{\mathrm{C}}^{\gamma}$ of $8 \times 10^{-16} \mathrm{~m}^{2} / \mathrm{s}$ is chosen, corresponding to a carbon content of $5 \mathrm{wt} \%$ and $200{ }^{\circ} \mathrm{C}$ according to Ågren. ${ }^{33}$

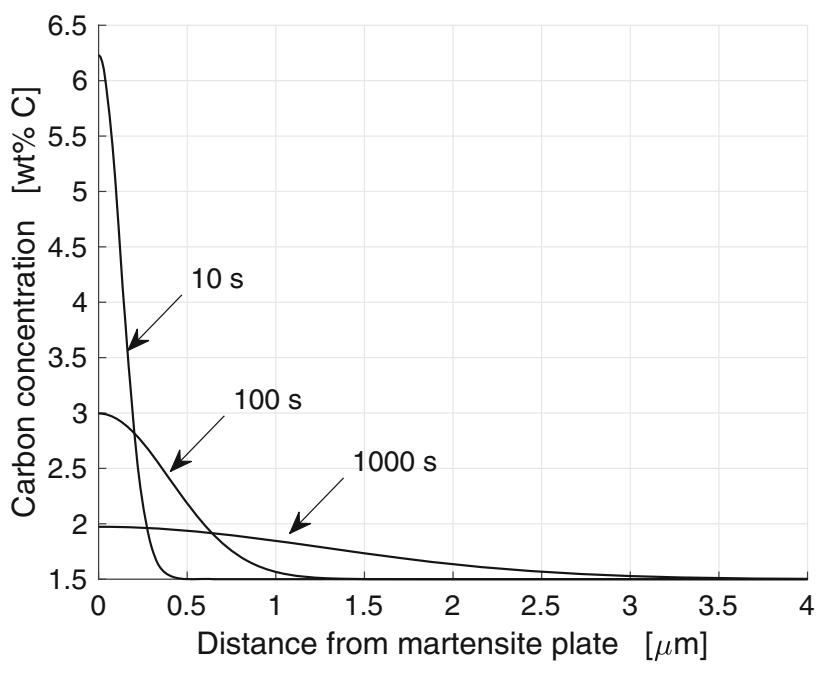

Figure 13. Estimated evolution of carbon concentration profile in austenite near recently formed martensite plate (left boundary). 
The result of the diffusion calculations using Eqn. 2 is presented in Figure 13. The evolution of the carbon concentration profile indicates that considerable diffusion of carbon in $\gamma$ over distances beyond a few micrometers is unlikely.

It seems safe to conclude that the martensite transformation did not contribute considerably to the observed depletion of carbon in the vicinity of graphite. As is indicated in Figure 12, the large area fraction of martensite found near graphite is more likely a consequence of carbon depletion than a cause of it. Sufficient carbon content of $\gamma$ suppresses martensite transformation, resulting in retained $\gamma^{43,46,47}$

\section{Conclusions}

Cross sections of CGI which was quenched during solidification were investigated using WDS-EPMA, with a focus on the distribution of carbon in regions which were austenite prior to quenching.

- After correction for a drift in the measured carbon concentrations over the concentration maps, the measured concentration in coarse $\mathrm{Fe}^{3} \mathrm{C}$ particles agreed reasonably with the expected stoichiometric ratio.

- The measured carbon concentration of austenite was generally higher near the liquid and lower near graphite. This is in qualitative agreement with the assumption of local equilibrium at their interfaces given that the system is undercooled below the eutectic temperature.

- The measured carbon concentration of austenite near graphite was considerably lower than the theoretical concentration for austenite in equilibrium with graphite at $1140{ }^{\circ} \mathrm{C}$. Numerical calculations indicate that this discrepancy is likely related to depletion of carbon in a zone around graphite during quenching.

- A numerical calculation indicates that an increase in the quench rate from $-300 \mathrm{~K} / \mathrm{s}$ to $-3000 \mathrm{~K} / \mathrm{s}$ reduces the carbon-depleted zone around spheroidal graphite from about $20 \mu \mathrm{m}$ to about $7 \mu \mathrm{m}$, leaving more of the carbon concentration profile unaffected by the quenching. A feasible approach to improve on the present experimental conditions is thus to increase the quench rate, for example, by quenching smaller material specimens.

- Measurements indicate that carbon migrated after martensite transformation. However, diffusion calculations suggest that this migration was limited to distances of a few micrometers and is unlikely to have contributed to the observed carbon-depleted zones around graphite.

- The measured carbon concentration of austenite near graphite was consistently lower in the central region of compacted graphite-austenite eutectic cells compared to near spheroidal graphite, by up to $0.3 \mathrm{wt} \%$. The source of these differences is unclear, but it seems reasonable that it reflects either a departure from or a displacement of the equilibrium concentration. It is not clear whether the differences were present prior to quenching. The differences were found to not be related to microsegregation of $\mathrm{Si}, \mathrm{Mn}$ or $\mathrm{Cu}$, since these concentrations are near equal in the compared regions.

\section{Acknowledgements}

Open access funding provided by Jönköping University. We extend our sincere gratitude to Kaj Grönlund and Gunilla Runnsjö, the engineers and operators of the electron microprobe, for their important contribution. This research was financed by VINNOVA, the Swedish Agency for Innovation, through the research project SPOFIC II, Grant No. (2013-04720), and by the Swedish Knowledge Foundation through the research project LeanCast, Grant No. (2018-0033). The projects are collaborations between Scania CV AB, Volvo Group Trucks Operation, SKF Mekan, Sintercast, CorrControl and Jönköping University.

Open Access This article is licensed under a Creative Commons Attribution 4.0 International License, which permits use, sharing, adaptation, distribution and reproduction in any medium or format, as long as you give appropriate credit to the original author(s) and the source, provide a link to the Creative Commons licence, and indicate if changes were made. The images or other third party material in this article are included in the article's Creative Commons licence, unless indicated otherwise in a credit line to the material. If material is not included in the article's Creative Commons licence and your intended use is not permitted by statutory regulation or exceeds the permitted use, you will need to obtain permission directly from the copyright holder. To view a copy of this licence, visit http://creativecommons. org/licenses/by/4.0/.

\section{REFERENCES}

1. R.J. Warrick, Spheroidal graphite nuclei in rare earth and magnesium inoculated irons. AFS Cast. Met. Res. J. 2(3), 97-108 (1966)

2. M.H. Jacobs, T.J. Law, D.A. Melford, M.J. Stowell, Identification of heterogeneous nuclei for graphite spheroids in chill-cast iron. Met. Technol. 3(1), 98-108 (1976). https://doi.org/10.1179/ 030716976803391610

3. B. Francis, Heterogeneous nuclei and graphite chemistry in flake and nodular cast irons. Metall. Trans. A 10(1), 21-31 (1979). https://doi.org/10.1007/ BF02686402

4. J.K. Solberg, M.I. Onsøien, Nuclei for heterogeneous formation of graphite spheroids in ductile cast iron. 
Mater. Sci. Technol. 17(10), 1238-1242 (2001). https://doi.org/10.1179/026708301101509313

5. H. Nakae, Y. Igarashi, Influence of sulfur on heterogeneous nucleus of spheroidal graphite. Mater. Trans. 43(11), 2826-2831 (2002). https://doi.org/10.2320/ matertrans.43.2826

6. G. Alonso, P. Larrañaga, D.M. Stefanescu, E. De la Fuente, A. Natxiondo, R. Suarez, Kinetics of nucleation and growth of graphite at different stages of solidification for spheroidal graphite iron. Int. J. Metalcasting 11(1), 14-26 (2017). https://doi.org/10. 1007/s40962-016-0094-7

7. S.-E. Wetterfall, H. Fredriksson, M. Hillert, Solidification process of nodular cast iron. J. Iron Steel Inst. 210(5), 323-333 (1972)

8. H. Fredriksson, J. Stjerndahl, J. Tinoco, On the solidification of nodular cast iron and its relation to the expansion and contraction. Mater. Sci. Eng. A 413, 363-372 (2005). https://doi.org/10.1016/j.msea.2005. 09.028

9. T. Owadano, K. Yamada, K. Torigoe, Quantitative metallographic study of the solidification of spheroidal graphite cast iron. Trans. Jpn. Inst. Met. 18(12), 871-878 (1977). https://doi.org/10.2320/mater trans1960.18.871

10. K.-C. Su, I. Ohnaka, I. Yamauchi, T. Fukusako, Computer simulation of solidification of nodular cast iron. Mater. Res. Soc. Proceed. 34, 181-190 (1985). https://doi.org/10.1557/PROC-34-181

11. R.E. Boeri (1989) The Solidification of Ductile Cast Iron, Doctoral Thesis, The University of British Colombia, 1989. https://doi.org/10.14288/1.0078465

12. S. Chang, D. Shangguan, D.M. Stefanescu, Modeling of the liquid/solid and the eutectoid phase transformations in spheroidal graphite cast iron. Metall. Trans. A 23(4), 1333-1346 (1992). https://doi.org/10.1007/ BF02665065

13. Q. Chen, E.W. Langer, P.N. Hansen, Stable solute boundary layer for liquid and volume change during eutectic solidification of spheroidal graphite iron.

J. Mater. Sci. Lett. 16(4), 249-252 (1997). https://doi. org/10.1023/A:1018572211806

14. G. Lesoult, M. Castro, J. Lacaze, Solidification of spheroidal graphite cast irons - I. Physical modeling. Acta Mater. 46(3), 983-995 (1998). https://doi.org/10. 1016/S1359-6454(97)00281-4

15. M.K. Bjerre, M. Azeem, P.D. Lee, J.H. Hattel, N.S. Tiedje, Revisiting models for spheroidal graphite growth. Mater. Sci. Forum 925, 118-124 (2018). https://doi.org/10.4028/www.scientific.net/MSF.925. 118

16. Y. Zhang, S.V. Subramanian, G.R. Purdy, Graphite growth in SG cast irons: simulation vs. experiment". Adv. Mat. Res. 4, 461-468 (1997). https://doi.org/10. 4028/www.scientific.net/AMR.4-5.461

17. J.C. Hernando, B. Domeij, D. González, J.M. Amieva, A. Diószegi, New experimental technique for nodularity and mg fading control in compacted graphite iron production on laboratory scale. Metall. Mater. Trans. A 48(11), 5432-5441 (2017). https:// doi.org/10.1007/s11661-017-4315-3

18. B. Domeij, J.C. Hernando, A. Diószegi, Size distribution of graphite nodules in hypereutectic cast irons of varying nodularity. Metall. Mater. Trans. B 49(5), 2487-2504 (2018). https://doi.org/10.1007/s11663018-1274-z

19. B. Domeij, J.C. Hernando, A. Diószegi, Quantification of dendritic austenite after interrupted solidification in a hypoeutectic lamellar graphite iron. Metallogr.

Microstruct. Anal. 5(1), 28-42 (2016). https://doi.org/ 10.1007/s13632-015-0250-0

20. E.M. Westin, K. Grönlund, G. Runnsjö, C.E. Cross, Use of electron microprobe analysis to explain metallurgical phenomena and their effect on properties when welding stainless steel. Weld. World 62(1), 55-69 (2018). https://doi.org/10.1007/s40194-0170522-1

21. P.T. Pinard, A. Schwedt, A. Ramazani, U. Prahl, S. Richter, Characterization of dual-phase steel microstructure by combined submicrometer EBSD and EPMA carbon measurements. Microsc. Microanal. 19(4), 996-1006 (2013). https://doi.org/10.1017/ S1431927613001554

22. J. Meija, B.C. Tyler, M. Berglund, A.B. Willi, P. De Bièvre, M. Gröning, E.H. Norman, J. Irrgeher, D.L. Robert, T. Walczyk, T. Prohaska, Atomic weights of the elements 2013 (IUPAC Technical Report). Pure Appl. Chem. 88(3), 265-291 (2016). https://doi.org/ 10.1515/pac-2015-0305

23. R.W. Heine, The Fe-C-Si solidification diagram for cast irons. Trans. Am. Foundrym. Soc. 94, 391-402 (1986)

24. W. Kurz, D.J. Fisher, Dendrite growth in eutectic alloys: the coupled zone. Int. Met. Rev. 24(1), 177-204 (1979). https://doi.org/10.1179/imtr.1979.24. 1.177

25. H. Jones, W. Kurz, Growth temperatures and the limits of coupled growth in unidirectional solidification of Fe-C eutectic alloys. Metall. Trans. A 11(8), 1265-1273 (1980). https://doi.org/10.1007/ BF02653480

26. R. Boeri, F. Weinberg, Microsegregation in ductile iron. AFS Trans. 89, 179-184 (1989)

27. R. Boeri, F. Weinberg, Microsegregation of alloying elements in cast iron. Cast Met. 6(3), 153-158 (1993). https://doi.org/10.1080/09534962.1993.11819142

28. C. Selig, J. Lacaze, Study of microsegregation buildup during solidification of spheroidal graphite cast iron. Metall. Mater. Trans. B 31(4), 827-836 (2000). https://doi.org/10.1007/s11663-000-0119-7

29. S. Vazehrad, J. Elfsberg, A. Diószegi, Study of microstructure and silicon segregation in cast iron using color etching and electron microprobe analysis. 
Mater. Charact. 104, 132-138 (2015). https://doi.org/ 10.1016/j.matchar.2014.09.008

30. B. Domeij, A. Diószegi, Inferring the development of microsegregation and microstructure in spheroidal and compacted graphite iron using EPMA-WDS, in 6th International Conference on Solidification Proceedings (2017), pp. 455-458

31. J. Eiken, E. Subasic, J. Lacaze, 3D phase-field computations of microsegregation in nodular cast iron compared to experimental data and CalPhad-based Scheil-prediction. Materialia (2019). https://doi.org/ 10.1016/j.mtla.2019.100538

32. A. Diószegi, É. Diószegi, J. Tóth, J.T. Svidró, Modelling and simulation of heat conduction in 1-D polar spherical coordinates using control volumebased finite difference method. Int. J. Numer. Methods Heat Fluid Flow 26(1), 2-17 (2016). https://doi.org/ 10.1108/HFF-10-2014-0318

33. J. Agren, A revised expression for the diffusivity of carbon in binary Fe-C austenite. Scripta Metall. 20(11), 1507-1510 (1986). https://doi.org/10.1016/ 0036-9748(86)90384-4

34. J. Ågren, Binary and multicomponent diffusion, in Characteristics of Materials, (Wiley, 2012), pp. 1-15. https://doi.org/10.1002/0471266965.com014.pub2

35. E. Lundbäck, ̊. Östlund, Kinetic aspects of eutectic Fe-Fe3C solidification. Mater. Sci. Eng. A 133, 823-826 (1991). https://doi.org/10.1016/09215093(91)90194-R

36. J. Lacaze, V. Gerval, Modelling of the eutectoid reaction in spheroidal graphite $\mathrm{Fe}-\mathrm{C}-\mathrm{Si}$ alloys. ISIJ Int. 38(7), 714-722 (1998). https://doi.org/10.2355/ isijinternational.38.714

37. F. Hellal, J. Lacaze, A. Hazotte, Initial stage of isothermal decomposition of austenite to ferrite and graphite in spheroidal graphite cast iron. Mater. Sci. Technol. 15(7), 773-778 (1999). https://doi.org/10. 1179/026708399101506562

38. M. Wessén, I.L. Svensson, Modeling of ferrite growth in nodular cast iron. Metall. Mater. Trans. A 27(8), 2209-2220 (1996). https://doi.org/10.1007/ BF02651875

39. A.J. Clarke, J.G. Speer, M.K. Miller, R.E. Hackenberg, D.V. Edmonds, D.K. Matlock, F.C. Rizzo, K.D. Clarke, E. De Moor, Carbon partitioning to austenite from martensite or bainite during the quench and partition (Q\&P) process: a critical assessment. Acta Mater. 56(1), 16-22 (2008). https://doi.org/10.1016/j. actamat.2007.08.051

40. M. Gouné, F. Danoix, S. Allain, O. Bouaziz, Unambiguous carbon partitioning from martensite to austenite in $\mathrm{Fe}-\mathrm{C}-\mathrm{Ni}$ alloys during quenching and partitioning. Scripta Mater. 68(12), 1004-1007 (2013). https://doi.org/10.1016/j.scriptamat.2013.02. 058

41. J.C. Hernando, E. Ghassemali, A. Diószegi, The morphological evolution of primary austenite during isothermal coarsening. Mater. Charact. 131, 492-499 (2017). https://doi.org/10.1016/j.matchar.2017.07.030

42. R.E. Pattle, Diffusion from an instantaneous point source with a concentration-dependent coefficient. Q J. Mech. Appl. Math. 12(4), 407-409 (1959). https://doi.org/10.1093/qjmam/12.4.407

43. J. Wang, S. Van Der Zwaag, Stabilization mechanisms of retained austenite in transformation-induced plasticity steel. Metall. Mater. Trans. A 32(6), 1527-1539 (2001). https://doi.org/10.1007/s11661-001-0240-5

44. T. Sourmail, C. Garcia-Mateo, Critical assessment of models for predicting the Ms temperature of steels. Comput. Mat. Sci. 34(4), 323-334 (2005). https://doi. org/10.1016/j.commatsci.2005.01.002

45. C.Y. Kung, J.J. Rayment, An examination of the validity of existing empirical formulae for the calculation of Ms temperature. Metall. Trans. A 13(2), 328-331 (1982). https://doi.org/10.1007/BF02643327

46. J. Wang, P.J. van der Wolk, S. van der Zwaag, Determination of martensite start temperature in engineering steels part I. Empirical relations describing the effect of steel chemistry. Mat. Trans. JIM 41(7), 761-768 (2000). https://doi.org/10.2320/mater trans 1989.41.761

47. M. Rahaman, W. Mu, J. Odqvist, P. Hedström, Machine learning to predict the martensite start temperature in steels. Metall. Mater. Trans. A 50(5), 2081-2091 (2019). https://doi.org/10.1007/s11661019-05170-8

Publisher's Note Springer Nature remains neutral with regard to jurisdictional claims in published maps and institutional affiliations. 